\title{
A Coordinated Charging Strategy for Electric Vehicles Based on Hierarchical Optimization
}

\author{
Jin-Yong SHI ${ }^{1, \mathrm{a}}$, Hui-Min KE ${ }^{1, \mathrm{~b}}$, Chong $\mathrm{LI}^{1, \mathrm{c}}$ and Jun-Jun SHAO ${ }^{1, \mathrm{~d},{ }^{*}}$ \\ ${ }^{1}$ Nari Technology Co., Ltd., Nanjing 211100, Jiangsu, China \\ a shijinyong@sgepri.sgcc.com.cn, b kehuimin@sgepri.sgcc.com.cn, \\ c lichong@sgepri.sgcc.com.cn, ${ }^{\mathrm{d}} 18705158318 @ 163 . c o m$ \\ *Corresponding author
}

Keywords: Electric vehicles; hierarchical optimization; peak load shifting; load fluctuation

\begin{abstract}
There are many electric vehicles charging stations in distribution network. Uncoordinated charging electric vehicles load is large and changes quickly; it brings risk to the operation of power grid. If taking each station as an independent unit, which will reduce the practicability of the proposed strategy because of the small consideration scope and incomplete information acquisition. Taking all electric vehicles in the distribution network as an object to study will lack the consideration about the differentiation of a single charging station. Also, controlling all electric vehicles directly through the control center has high demand on reliability. And it is difficult to implement. Given this, the paper used the hierarchical control method to control the electric vehicles in the charging stations and studied charging strategy based on hierarchical optimization. The upper layer used the distribution system load variance as an objective function to establish a model and peak load shifting. The lower level model took the actual charging power deviation and load variance of the charging station into account to reduce the load fluctuation of the charging station. The paper used function fmincon to solve the upper level model and used CPLEX to solve the lower layer model. Finally, using a modified IEEE 33-bus system with 3 EVAs to verify the feasibility of the model and method, which reduced frequency between the control center and electric vehicles. Also, it cuts peak load and reduces load fluctuations of charging stations.
\end{abstract}

\section{Introduction}

With the rapid development of the economy, the demand for energy in countries around the world is increasing. The negative effects brought about by traditional fossil fuels have gradually emerged and continuously restrict the sustainable development of the economy [1]. In order to solve the dilemma, it is necessary to find energy sources with higher energy efficiency, better energy-saving and emission-reducing effects to optimize the existing energy structure. Under this background, the development of electric vehicles not only can revitalize the automobile industry, inject fresh vitality into the automotive industry, but also greatly reduce energy consumption and promote energy conservation and emission reduction. Therefore, electric vehicles have become a hot spot for development in various countries in recent years [2]. However, uncoordinated charging of vehicles influences the grid, so it is very important to study a suitable charging strategy for electric vehicles. The electricity price guidance method means that the charging service provider formulates the time-of-use price according to the specific situation and then guides the users so that the users can respond autonomously to his own trip demand and electricity price, and ultimately achieve the purpose of coordinated charging. Reference [3] formulated the optimal valley price time period to guide the charging behavior of users, the difference between peak and valley load of the grid is greatly reduced. Reference [4] aimed at the slow charging mode of electric private cars; the corresponding model is established with the lowest charging cost of the user and the earliest start time of the charging period. The optimal time-of-use price period with the smallest peak-valley difference is obtained by solving the model. Reference [5] proposed strategy is mainly divided into two parts. Firstly, the most appropriate charging load curve is obtained by taking the minimum cost of electricity purchase at the charging station as the objective function, and then the objective function is 
modeled by minimizing the variance of the actual charging load curve and the tar-get load curve. Using PSO algorithm to obtain the optimal peak-to-valley time and optimal time-of-use price. Reference [6] based on the charging load of large-scale electric vehicles, they were modeled separately without considering the V2G responsivity and considering the V2G responsivity. Both introduced the valley price time period as a variable. The division of the peak-valley electricity price period obtained by solving the model can effectively improve the operation safety of the distribution network. Although the electricity price guidance method can shift the charging load of electric vehicles from the peak price period to the valley price period, it is easy to form a new load peak during the valley price period, which does not completely solve the problems caused by the uncoordinated charging of electric vehicles. Centralized control mainly refers to the centralized management of each electric vehicle through the controller [7]. Reference [8] combined the forecasting load of unconnected electric car charging with the traditional real-time charging control strategy to establish a new model, and used the rolling optimization algorithm to obtain the optimal charging power of the electric vehicle. Reference [9] Based on the peak-to-peak electricity price, the combination of on-line optimization and off-line optimization controls the charging power of the electric vehicle via the controller, so that the total electricity load is lower than the cell power limit. So the values are optimized at the end of each control period. Reference [10,11] used centralized control strategies to optimize various objectives, including reducing power loss, minimizing load variance, and maximizing the load factor. This kind of control method requires an upper-level control organization to collect information on electric vehicles, including the initial SOC (State of charge), the SOC that the user needs when reaching the end of charging, and the time it takes to leave the charging system. The difficulty of this centralized optimization method increases with the increasing number of electric vehicles, coupled with the limitations of existing communication technologies. It is unrealistic to control and charge each electric car through the upper control center. So it is necessary to consider the hierarchical control mode and interact the charging station with the control center. This kind of control mode for issuing electric vehicles through layers of instructions avoids the heavy storage and computation burden of the control center, and at the same time greatly reduces the requirements on the reliability and bandwidth of the communication network. Reference [12] used hierarchical optimization model, but the impact of the load fluctuations of the charging station itself on the tie line is not taken into account in the lower level model.

Based on the above reasons, the upper layer model considers peak load filling. In the lower layer model, it is considered that the charging power should match the guidance power as much as possible. On the other hand, the load fluctuation of the charging station itself should be minimized. The fmincon function is used to solve the up-per model, CPLEX is used to solve the lower model, and the IEEE 33-node test system with three charging stations is used as an example to verify the proposed method.

\section{Hierarchical Control Method for Electric Vehicles}

For the hierarchical control proposed in this paper, the control model structure constructed as shown in Figure 1, the entire hierarchical control system is divided into control center, electric vehicle charging station, station charging equipment. The control center of the figure is connected with the external network and is the highest control layer of the system. Its main task is to coordinate the charging power of each electric vehicle charging station and reduce the impact of the charging load on the power grid. 


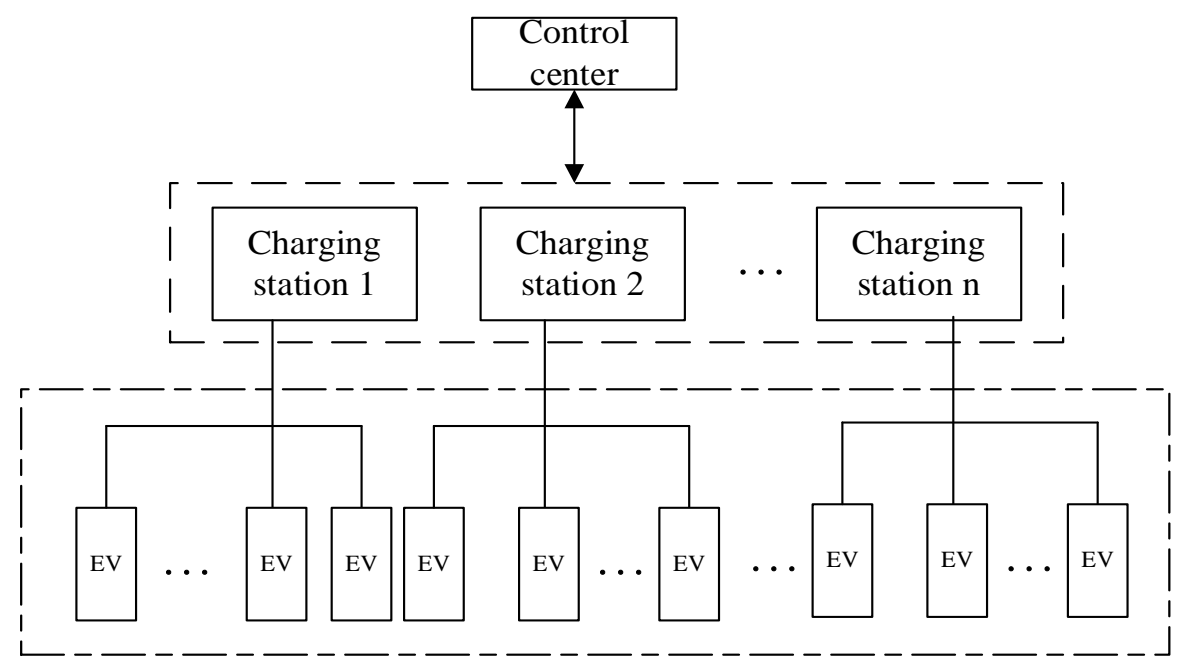

Fig. 1 Frame chart of electric vehicle stratified control

In order to facilitate the development of suitable strategies for upper-level control centers and electric vehicle charging stations, this paper uses the method described in reference [13] to analyze the results of the reference [14] and the Federal Highway Administration of the United States Department of Transportation in 2009 for families across the United States [15], It can roughly get the arrival time, the probability of leaving the station and the probability density function of the charging interval mileage of the vehicles in the charging station in the commercial area during the working day, as shown in formulas (1) to (3).

$$
f_{l}(x)= \begin{cases}\frac{1}{\sqrt{2 \pi} \sigma_{l}} \exp \left(-\frac{\left(x-\mu_{1}\right)^{2}}{2 \sigma_{1}^{2}}\right) & 0<x \leq \mu_{1}+12 \\ \frac{1}{\sqrt{2 \pi \sigma_{l}}} \exp \left(-\frac{\left(x-24-\mu_{1}\right)^{2}}{2 \sigma_{1}^{2}}\right) & \mu_{1}+12 \leq 24 .\end{cases}
$$

Where, $\mu_{1}=8.7 ; \sigma_{l}=3.3$.

$$
f_{a}(x)=\left\{\begin{array}{l}
\frac{1}{\sqrt{2 \pi} \sigma_{a}} \exp \left(-\frac{\left(x+24-\mu_{a}\right)^{2}}{2 \sigma_{a}^{2}}\right) 0<x \leq \mu_{a}+12 \\
\frac{1}{\sqrt{2 \pi \sigma_{a}}} \exp \left(-\frac{\left(x-\mu_{a}\right)^{2}}{2 \sigma_{a}^{2}}\right) \quad \mu_{a}+12 \leq 24
\end{array}\right.
$$

Where, $\mu_{\mathrm{a}}=17.5 ; \sigma_{\mathrm{a}}=3.34$.

$$
f_{t}(x)=\frac{1}{\sqrt{2 \pi} \sigma_{t} x} \exp \left(-\frac{\left(\ln x-\mu_{t}\right)^{2}}{2 \sigma_{t}^{2}}\right) .
$$

Where, $\mu_{\mathrm{t}}=3.1 ; \sigma_{\mathrm{t}}=1.1$.

\section{Hierarchical Optimization Model for Electric Vehicles}

\section{Upper Optimization Model}

The electric vehicle control center considers peak load shifting, and uses the minimum load variance of the distribution network system as an objective function to establish an optimization model to optimize the power steering curve delivered to the charging station. The mathematical expression is as follows:

$$
F_{1}=\frac{1}{\mathrm{~T}} \sum_{\mathrm{t}=1}^{\mathrm{T}}\left(\mathrm{P}_{\mathrm{b}, \mathrm{t}}+\sum_{\mathrm{n}=1}^{\mathrm{N}_{0}} \mathrm{P}_{\mathrm{s}, \mathrm{n}, \mathrm{t}}-\overline{\mathrm{P}}\right)^{2} .
$$




$$
\overline{\mathrm{P}}=\frac{1}{\mathrm{~T}} \sum_{\mathrm{t}=1}^{\mathrm{T}}\left(\mathrm{P}_{\mathrm{b}, \mathrm{t}}+\sum_{\mathrm{n}=1}^{\mathrm{N}_{0}} \mathrm{P}_{\mathrm{s}, \mathrm{n}, \mathrm{t}}\right)
$$

Where, $\mathrm{T}$ is control period; $\mathrm{P}_{\mathrm{b}, \mathrm{t}}$ is base load; $\mathrm{P}_{\mathrm{s}, \mathrm{n}, \mathrm{t}}$ is load guidance curve followed by electric vehicle charging stations, $\mathrm{P}_{\mathrm{s}, \mathrm{n}, \mathrm{t}} \geq 0 ; \mathrm{N}_{0}$ is thenumber of charging stations

The constraints are as follows:

$$
\sum \mathrm{P}_{\mathrm{G}, \mathrm{i}, \mathrm{t}}=\sum \mathrm{P}_{\mathrm{D}, \mathrm{i}, \mathrm{t}}+\sum \mathrm{P}_{\mathrm{s}, \mathrm{n}, \mathrm{t}}+\sum \mathrm{P}_{\text {loss }}
$$

Where, $\mathrm{P}_{\mathrm{G}, \mathrm{i}, \mathrm{t}}$ is generator output; $\mathrm{P}_{\mathrm{D}, \mathrm{i}, \mathrm{t}}$ is load demand; $\mathrm{P}_{\text {loss }}$ is grid loss.

$$
\mathrm{V}_{\min } \leq \mathrm{V}_{\mathrm{i}, \mathrm{t}} \leq \mathrm{V}_{\text {max }} \text {. }
$$

Where, $\mathrm{V}_{\mathrm{i}, \mathrm{t}}$ is node voltage at time $\mathrm{t} ; \mathrm{V}_{\max }, \mathrm{V}_{\min }$ are upper and lower limitation of node voltage.

$$
\left|\mathrm{P}_{\mathrm{l}, \mathrm{t}}\right| \leq \mathrm{P}_{\mathrm{l} \text { max }} \text {. }
$$

Where, $\mathrm{P}_{1, \text { max }}$ is line $\mathrm{l}$ transmission power cap; $\mathrm{P}_{1, \mathrm{t}}$ is transmission power of line $\mathrm{l}$ at time $\mathrm{t}$.

$$
0 \leq \mathrm{P}_{\mathrm{s}, \mathrm{n}, \mathrm{t}} \leq \sum_{\mathrm{i}=1}^{\mathrm{N}_{1}} \mathrm{AP}_{\mathrm{n}, \mathrm{i}, \mathrm{t}}
$$

Where, $\mathrm{P}_{n, \mathrm{i}, \mathrm{t}}$ is the $\mathrm{i}$-th electric car charging power in electric vehicle charging station $\mathrm{n}$ at time $\mathrm{t} ; \mathrm{A}$ is the $\mathrm{i}$-th electric vehicle arrives at the charging station $\mathrm{n} ; \mathrm{N}_{1}$ is the number of electric vehicles.

\section{Lower Optimization Model}

In order to formulate a coordinated charging strategy for an electric vehicle within a charging station, the total load peak-to-valley difference of the distribution system must be considered first. Moreover, the peak-to-valley difference of the charging station load is too large; it will bring a great impact to the connection line between the charging station and the power grid. Therefore, the peak-to-valley difference of the charging load of the charging station must also be considered. The mathematical expression is as follows:

$$
\begin{aligned}
& \mathrm{F}_{2}=\lambda_{1} \sum_{\mathrm{t}=1}^{\mathrm{T}}\left(\mathrm{P}_{\mathrm{sc}, \mathrm{n}, \mathrm{t}^{-}}-\frac{1}{\mathrm{~T}} \sum_{\mathrm{t}=1}^{\mathrm{T}} \mathrm{P}_{\mathrm{sc}, \mathrm{n}, \mathrm{t}}\right)^{2}+\lambda_{2} \sum_{\mathrm{t}=1}^{\mathrm{T}}\left(\mathrm{P}_{\mathrm{s}, \mathrm{n}, \mathrm{t}}-\mathrm{P}_{\mathrm{sc}, \mathrm{n}, \mathrm{t}}\right)^{2} . \\
& \mathrm{P}_{\mathrm{sc}, \mathrm{n}, \mathrm{t}} \leq \sum_{\mathrm{i}=1}^{\mathrm{m}} \mathrm{AP}_{\mathrm{n}, \mathrm{i}, \mathrm{t}} . \\
& P_{n, i, t}=\left\{\begin{array}{cc}
P_{n, i, c h} & \alpha=1 \\
0 & \alpha=0 .
\end{array}\right.
\end{aligned}
$$

Where, $\alpha=0$ means electric vehicle does not charge ; $\alpha=1$ means electric vehicle is charging.

The constraints are as follows:

$$
\begin{gathered}
S_{i, t+1}= \begin{cases}S_{i, t}+\frac{P_{n, i, c h} \eta t}{Q_{i}} & \alpha=1 \\
S_{i, t} & \alpha=0 .\end{cases} \\
S_{\min } \leq S_{i, t} \leq S_{\max } .
\end{gathered}
$$

Where, $\mathrm{S}_{\mathrm{i}, \mathrm{t}}$ is the SOC of the $\mathrm{i}$-th electric vehicle in the charging station at the end of time period $\mathrm{t}$; $\eta$ is Charging efficiency of electric vehicle; $Q_{i}$ is the battery capacity of the i-th electric car in the charging station; $\Delta \mathrm{t}$ is the length of a control period; $\mathrm{S}_{\max }, \mathrm{S}_{\min }$ are upper and lower limitation of Power battery SOC; $\mathrm{P}_{n, \mathrm{i}, \mathrm{ch}}$ is the i-th electric car charging power in electric vehicle charging station n.

$$
\alpha=0 \mathrm{t}<\mathrm{t}_{\mathrm{a}} \text { or } \mathrm{t}>\mathrm{t}_{\mathrm{l}} \text {. }
$$

Where, $t_{a}$ is the moment of Electric car access charging system; $t_{l}$ is the oment of Electric car leaves charging system.

$$
\mathrm{S}_{\mathrm{i}, \mathrm{tl}} \geq \mathrm{S}_{\mathrm{i}}
$$


Where, $S_{i, t l}$ is the SOC of electric vehicles when leaving the charging system; $S_{i}$ is the SOC that the user needs to reach.

\section{Solution}

The upper model is a multivariable constrained quadratic programming problem. This paper can be solved by function fmincon. The lower model belongs to 0-1 planning and is a special kind of integer programming problem. The traditional intelligent algorithm solves the problem slowly. In this paper, the CPLEX solver is used to solve the problem quickly and the solution result is accurate. The specific solution flow is shown in Fig.2.

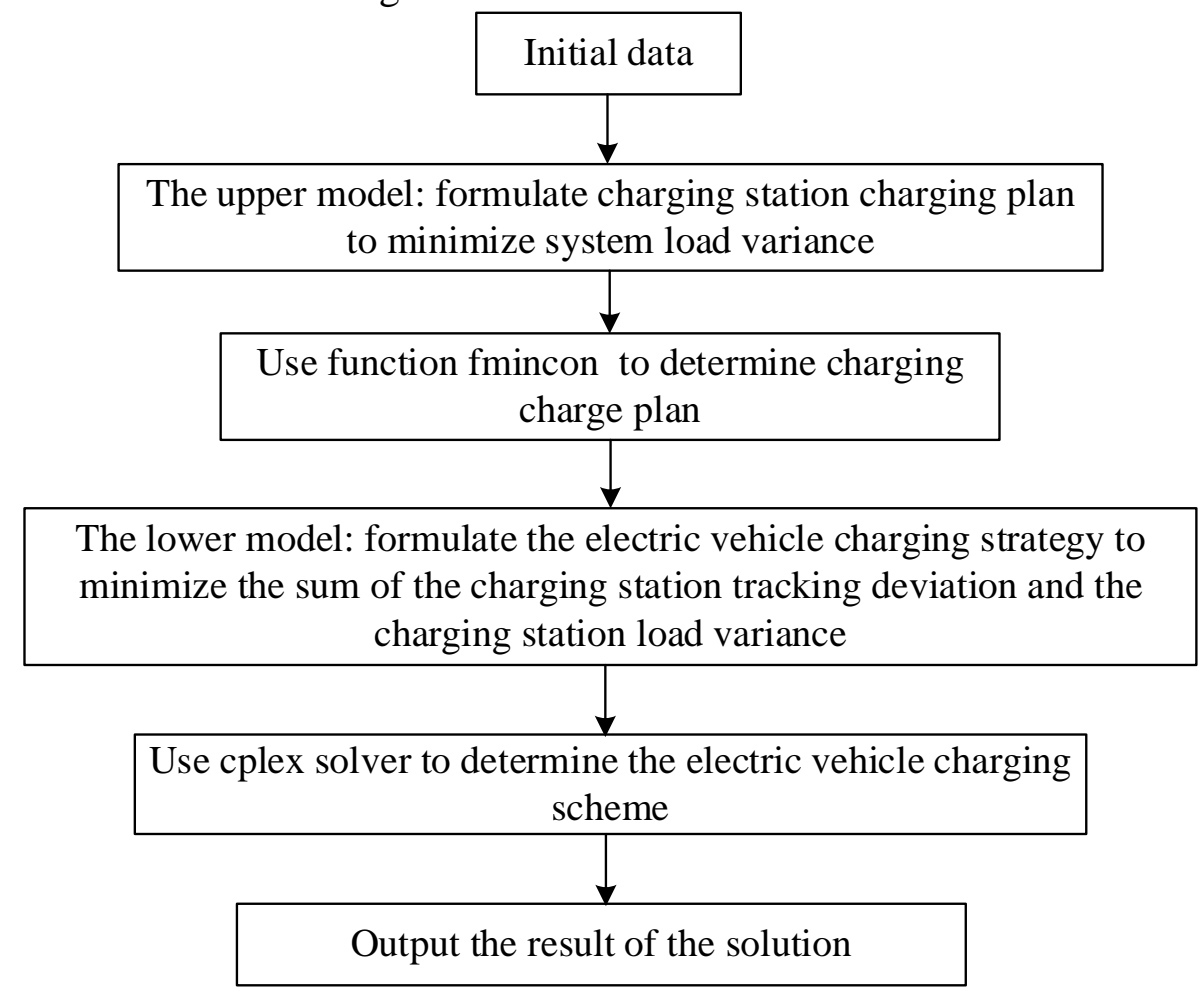

Fig. 2 Flow chart for solving hierarchical optimal model for electric vehicles charging

\section{Case Studies}

The modified IEEE33 node system is used as the test system, shown in Figure 3. The IEEE33 node distribution network contains 33 nodes, 32 branches, and 5 contact switch branches. The detailed data of the branch is shown in Table A1. Distribution system load data and changes are shown in Table A2 and Figure A1. Node 0 is set as a balanced node. The generator is accessed at node 15 and node 19. Data is shown in Table 1. The three electric vehicle charging stations are connected to node 11, node 20 and node 28. The total number of electric vehicles accepted every day is shown in Table 2, and the charging power of each electric vehicle is $3 \mathrm{~kW}$.

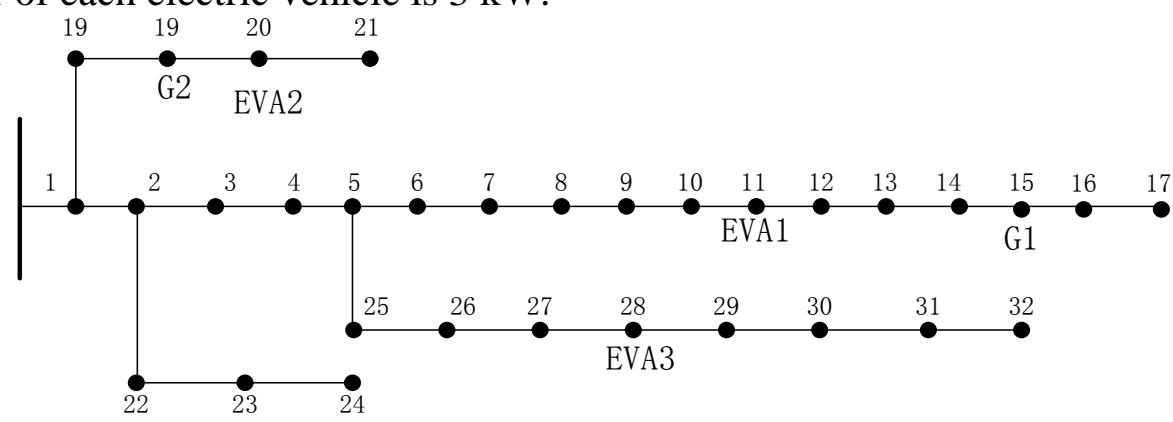

Fig. 3 Topology structure of the IEEE33 node distribution network 
Table 1 Data of generators

\begin{tabular}{|c|c|c|}
\hline generator & Active power upper limit [MW] & Active power lower limit [MW] \\
\hline G1 & 46 & 13 \\
\hline G2 & 40 & 10 \\
\hline
\end{tabular}

Table 2 Numbers of electric vehicles in charging stations in business area

\begin{tabular}{|c|c|}
\hline Charging station & Number \\
\hline EVA1 & 800 \\
\hline EVA2 & 760 \\
\hline EVA3 & 840 \\
\hline
\end{tabular}

Using the charging strategy proposed in this article to charge electric vehicles,distribution system load increases on the original basis.Comparing it with the uncoordinated load curve of the distribution network system, as shown in Figure 4. More detailed data of distribution system load peaks and valleys is shown in Table 3.The charging curve of charging station 1 of coordinated and uncoordinated charging comparison is shown in Fig. 4.

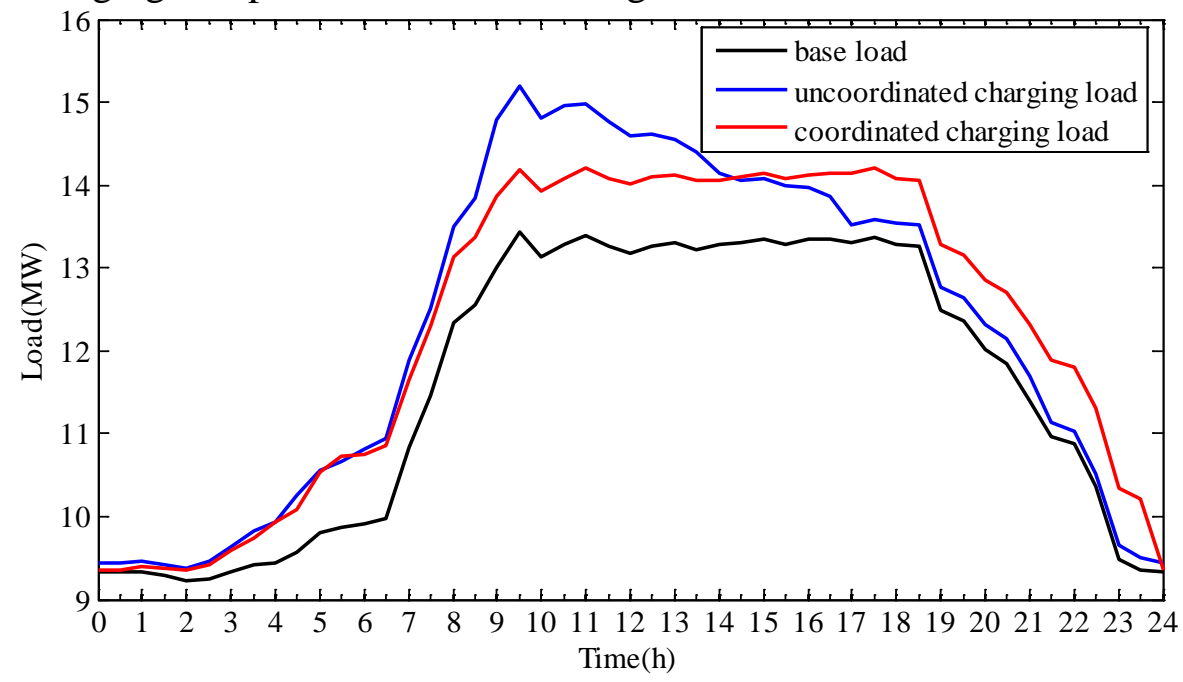

Fig. 4 Comparison of free charging mode and optimal charging mode

Table 3 Comparison of distribution network system load

\begin{tabular}{|c|c|c|}
\hline Mode & Peak[MW] & Valley[MW] \\
\hline Base load & 13.50 & 9.22 \\
\hline $\begin{array}{c}\text { Uncoordinated } \\
\text { charging }\end{array}$ & 15.20 & 9.38 \\
\hline Coordinated charging & 14.21 & 9.36 \\
\hline
\end{tabular}




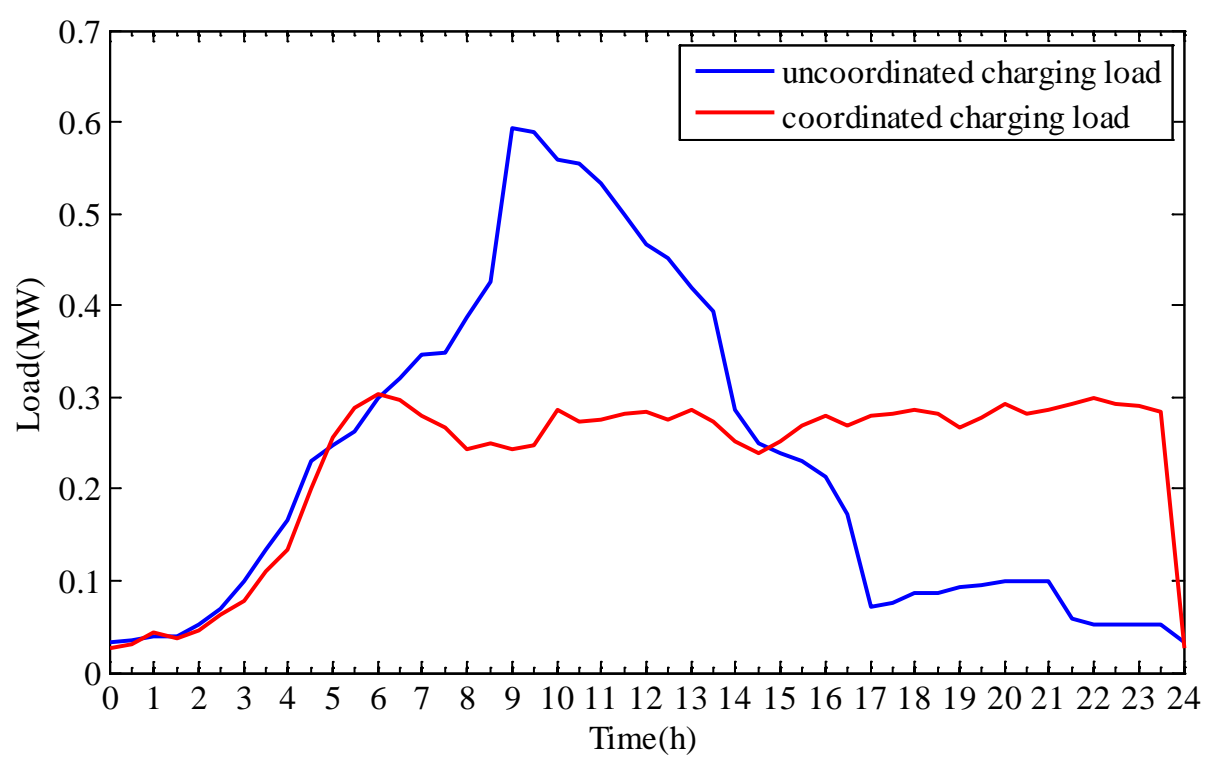

Fig. 5 Comparison of Charging station 1 load

The data in the figure and table can be clearly seen that the coordinated charging strategy studied in this paper can greatly reduce the peak load under the premise of guaranteeing the user's charging demand. Although the valley of the load has not changed much, the load curve of the entire distribution network system tends to slow down, reducing the impact on the grid. At the same time, the load peak load of the charging station is also reduced and becomes more stable.

\section{Conclusions}

In this paper, the electric vehicle charging strategy based on hierarchical optimization is established. The upper model uses the load variance of the distribution system as the objective function, while the lower model focuses on the actual charging power deviation of the charging station and the charging station load variance. For the two models, fmincon and CPLEX were used to solve the problem. Finally, an IEEE33 node test system including three charging stations was used as an example to verify the proposed method, which greatly reduced the number of communication between the system control center and electric vehicles. At the same time, it has played a good role in cutting peaks and reducing load fluctuations of charging stations.

\section{Acknowledgement}

This Project was financially supported by the National Key Technologies R\&D Program of MOST (2016YFB0101800), Science and Technology Program of SGCC (Operation Safety and Interconnection Technology for Electric Infrastructure).

\section{References}

[1] LUO Zhuowei, HU Zechun, SONG Yonghua, et al. Study on plug-in electric vehicles charging load calculating[J].Automation of Electric Power Systems, 2011,35 (14): 36-42.

[2] Ferdowsi M.Vehicle fleet as a distributed energy storage system for the power grid[C]// Proceedings of IEEE Power \& Engineering Society General Meeting, July 26-30, 2009, Calgary, Canada: $1-2$.

[3] GE Shaoyun, HUANG Liu, LIU Hong. Optimization of peak-valley TOU power price time-period in ordered charging mode of electric vehicle [J]. Power System Protection and Control, 2012, 40 (10):1-5. 
[4] SUN Xiaoming, WANG Wei, SU Su, et al. Coordinated charging strategy for electric vehicles based on time-of-use price[J].Automation of Electric Power System,2013,37 (1) :191-195.

[5] CHANG Fangyu, HUANG Mei, ZHANG Weige. Research on coordinated charging of electric vehicles based on TOU charging price [J]. Power System Technology, 2016, 40(09):2609-2615.

[6]WANG Bo, AI Xin. Coordinated charging of peak-valley time-period optimization by considering V2G user reactivity [J]. Modern Electric Power, 2016, 33(02):39-44.

[7]P Richardson Flynn, A Keane. Local Versus centralized charging strategies for electric vehicles in low voltage distribution systems[J].IEEE Transactions on Smart Grid,2012,3 (2):1020-1028.

[8]LI Zhengshuo, GUO Qinglai, SUN Hongbin, et al.Real-time charging optimization method considering vehicle charging prediction [J]. Automation of Electric Power Systems, 2014, 38(09):61-68.

[9]QI Xianjun, LI Dongwei,JI Shuyan. A coordinated charging control strategy for electric vehicles in residential area with power limitation [J]. Power System Technology, 2016, 40(12):3715-3721.

[10]K Clement, E Haesen, J Driesen. Coordinated charging of multiple plug-in hybrid electric vehicles in residential distribution grids[C]. Power Systems Conference \& Exposition, 2009,107 (1):1-7.

[11]AF Ali, M Abdel-Akher, Z Ziadi,et al.Coordinated charging of plug-in hybrid electric vehicle for voltage profile enhancement of distribution systems[C].IEEE International Conference on Power Electronics \& Drive Systems, 2013 :399-404.

[12]YAO Weifeng, ZHAO Junhua, WEN Fushuan,et al. A charging and discharging dispatching strategy for elec-tric vehicles based on bi-level optimization. [J]. Auto-mation of Electric Power Systems, 2012, 36(11):30-37.

[13]TIAN Liting1, SHI Shuanglong1, JIA Zhuo .A Statistical Model for Charging Power Demand of Electric Vehicles [J]. Power System Technology, 2010, 34 (11) :126-130.

[14]Wang Rui. Research on Parking Demand Forecasting Based on Regional Location Analysis [D]. Kunming University of Science and Technology,2010.

[15]Federal Highway Administration, U.S. Department of Transporation.2009 national household travel survey [EB/OL]. [2011-09-15]. http://nhts.ornl.gov.

Appendix A

Table A1 Branch data

\begin{tabular}{|c|c|c|c|c|c|c|c|c|c|}
\hline $\begin{array}{c}\text { Line } \\
\text { number }\end{array}$ & $\begin{array}{c}\text { Starting } \\
\text { node }\end{array}$ & $\begin{array}{c}\text { End } \\
\text { node }\end{array}$ & $\begin{array}{c}\text { Resistance } \\
{[\Omega]}\end{array}$ & $\begin{array}{c}\text { Reactance } \\
{[\Omega]}\end{array}$ & $\begin{array}{c}\text { Line } \\
\text { number }\end{array}$ & $\begin{array}{c}\text { Starting } \\
\text { node }\end{array}$ & $\begin{array}{c}\text { End } \\
\text { node }\end{array}$ & $\begin{array}{c}\text { Resistance } \\
{[\Omega]}\end{array}$ & $\begin{array}{c}\text { Reactance } \\
{[\Omega]}\end{array}$ \\
\hline 1 & 0 & 1 & 0.182 & 0.147 & 17 & 16 & 17 & 0.824 & 0.674 \\
\hline 2 & 1 & 2 & 0.591 & 0.352 & 18 & 1 & 18 & 0.236 & 0.265 \\
\hline 3 & 2 & 3 & 0.457 & 0.286 & 19 & 18 & 19 & 1.602 & 1.454 \\
\hline 4 & 3 & 4 & 0.472 & 0.214 & 20 & 19 & 20 & 0.515 & 0.575 \\
\hline 5 & 4 & 5 & 0.92 & 0.813 & 21 & 20 & 21 & 0.819 & 1.373 \\
\hline 6 & 5 & 6 & 0.283 & 0.729 & 22 & 2 & 22 & 0.512 & 0.483 \\
\hline 7 & 6 & 7 & 0.824 & 0.728 & 23 & 22 & 23 & 0.913 & 0.812 \\
\hline 8 & 7 & 8 & 1.120 & 0.245 & 24 & 23 & 24 & 0.996 & 0.801 \\
\hline 9 & 8 & 9 & 1.144 & 0.831 & 25 & 5 & 25 & 0.312 & 0.204 \\
\hline 10 & 9 & 10 & 0.265 & 0.165 & 26 & 25 & 26 & 0.384 & 0.247 \\
\hline
\end{tabular}




\begin{tabular}{|c|c|c|c|c|c|c|c|c|c|}
\hline $\begin{array}{c}\text { Line } \\
\text { number }\end{array}$ & $\begin{array}{c}\text { Starting } \\
\text { node }\end{array}$ & $\begin{array}{c}\text { End } \\
\text { node }\end{array}$ & $\begin{array}{c}\text { Resistance } \\
{[\Omega]}\end{array}$ & $\begin{array}{c}\text { Reactance } \\
{[\Omega]}\end{array}$ & $\begin{array}{c}\text { Line } \\
\text { number }\end{array}$ & $\begin{array}{c}\text { Starting } \\
\text { node }\end{array}$ & $\begin{array}{c}\text { End } \\
\text { node }\end{array}$ & $\begin{array}{c}\text { Resistance } \\
{[\Omega]}\end{array}$ & $\begin{array}{c}\text { Reactance } \\
{[\Omega]}\end{array}$ \\
\hline 11 & 10 & 11 & $0 . .474$ & 0.238 & 27 & 26 & 27 & 1.159 & 1.037 \\
\hline 12 & 11 & 12 & 1.568 & 1.255 & 28 & 27 & 28 & 0.904 & 0.806 \\
\hline 13 & 12 & 13 & 0.843 & 0.645 & 29 & 28 & 29 & 1.074 & 1.063 \\
\hline 14 & 13 & 14 & 0.691 & 0.626 & 30 & 29 & 30 & 1.074 & 1.036 \\
\hline 15 & 14 & 15 & 0.843 & 0.645 & 31 & 30 & 31 & 0.415 & 0.462 \\
\hline 16 & 15 & 16 & 1.389 & 1.821 & 32 & 31 & 32 & 0.441 & 0.632 \\
\hline
\end{tabular}

Table A2 Load data

\begin{tabular}{|c|c|c|c|c|c|c|c|c|c|}
\hline Node & Load[MW] & Node & Load[MW] & Node & Load[MW] & Node & Load[MW] & Node & Load[MW] \\
\hline 0 & 0 & 7 & 0.745 & 14 & 0.155 & 21 & 0.24 & 28 & 0.510 \\
\hline 1 & 0.355 & 8 & 0.155 & 15 & 0.13 & 22 & 0.245 & 29 & 0.705 \\
\hline 2 & 0.315 & 9 & 0.155 & 16 & 0.195 & 23 & 1.775 & 30 & 0.560 \\
\hline 3 & 0.51 & 10 & 0.125 & 17 & 0.210 & 24 & 1.790 & 31 & 0.785 \\
\hline 4 & 0.185 & 11 & 0.155 & 18 & 0.280 & 25 & 0.155 & 32 & 0.580 \\
\hline 5 & 0.155 & 12 & 0.155 & 19 & 0.280 & 26 & 0.165 & & \\
\hline 6 & 0.745 & 13 & 0.510 & 20 & 0.250 & 27 & 0.155 & & \\
\hline
\end{tabular}

Note: The data in the table is 9:00 load and the total node load is 13.5 MW.

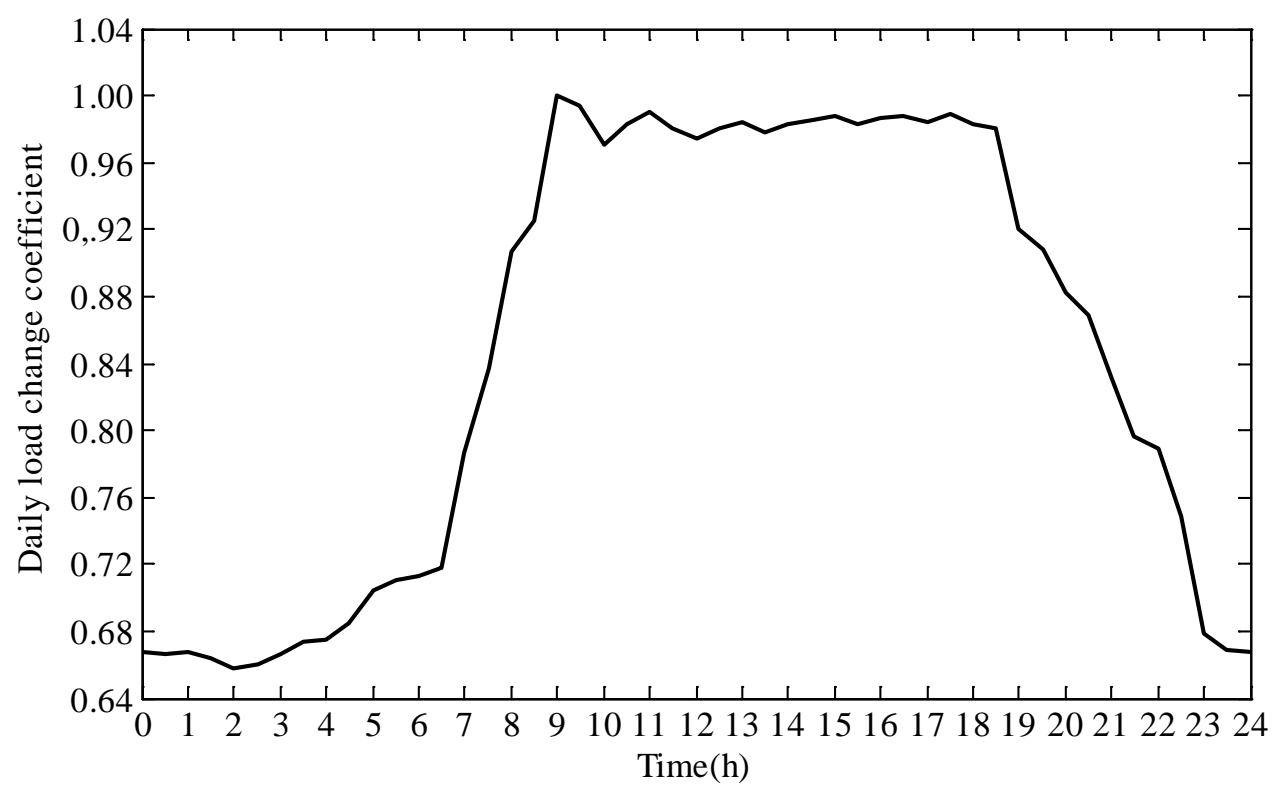

Fig. A1 Variation curve of daily load ratio 